\title{
A Tale of Two Cities, or The Long and the Short of It
}

Having stolen a title from Charles Dickens, I suppose I am constrained from using his opening line, ${ }^{*}$ too. Anyway, it does not quite work, because the two cities in question are Boston and San Francisco, which I associate primarily with the Fall and Spring Materials Research Society meetings, and therefore only the Best of Times.

I was introduced to Boston as a postdoc at the Massachusetts Institute of Technology, fresh from England. As far as transatlantic culture shock goes, Boston is a relatively benign experience for a cityraised Englishman, but many things in my new environment still produced amazement or amusement. Although these could fill many POSTERMINARIES columns, I shall address only the First Law of American Rhetoric: that you should never use a short or clear word where a longer or more obscure one will do. Plus its various corollaries: If a longer word is unavailable, use a phrase; if you cannot create a phrase, add some syllables to make a longer word. This law has been both obeyed and countermanded with only two words in the brilliant bumper sticker "Eschew Obfuscation." Write on!

Examples of the First Law are so common that, over time, we become immune to them, but try to remember to ask yourself, next time you fly, why the cabin crew uses the phrase "at this time" in place of "now." I guess it just makes it sound more important or something. Why do we see authors at MRS meetings (none of you good readers, I am sure) pointing to projected images of little chunks of matter and calling them "particulates?" How did the noun "particle" transform to the adjectival phase "particulate" and retain that form upon retransformation into the nounal phase field? Is a linguistic Carnot cycle in play here, indicating the intrusion of a kind of verbal entropy, or is the word merely a supercooled, nonequilibrium form that will eventually retransform upon further annealing? Another thermodynamically misfavored word is "homogenous," which results from the transformation under equilibrium conditions of the adjectival "homogeneous" to the verb "homogenize" followed by a rapid transformation back to the adjective. The rapidity of the second transformation prevents

"It was the best of times, it was the worst of times. the formation of the equilibrium ph(r)ase, by suppressing the thought process. "Homogenous" is an anomaly also because it apparently flaunts the First Law by having fewer syllables than its parent ph(r)ase. This will probably make it much less stable than the nounal particulate.

The greater Boston area is perhaps the home of the First Law of American Rhetoric. It is only a little surprising that MIT did not extend its name even further by substituting "Institution" for "Institute," thereby gaining a syllable. Of course, the name is already so long that when it is printed in full along the length of a pen or a pencil, it requires a special long-life writing tool. The scene of one of my many diatribes against the First Law was a street in Boston, where I was walking with an MIT colleague who had foolishly asked about my first impressions of life in the United States. Casting my eyes about for an illustrative example (knowing full well that one would quickly come to hand), I found on the side of a bus the letters MBTA. Every Bostonian knows that these stand for the "Massachusetts Bay Transportation Authority," but every Londoner (from an age before privatization) knew that their buses were operated by "London Transport." Those two words used to appear on the sides of the famous big red buses, with the final " $\mathrm{t}$ " enlarged and capitalized, presumably to balance the look of the logo, but also to emphasize that this is, indeed, the end of the word. No superfluous syllables, here. "What is the difference," I ranted, "between 'transport' and 'transportation?' Why the extra two syllables?" As I warmed to my topic, doubtless egged on my interlocutor, I pondered whether Shakespeare would have penned phrases like "Oh, what transportation of delight," had he been born in the American colonies. Well, Winston Churchill observed that Britain and the United States are "two nations divided by a common tongue," and my complaint, indeed, turned into a moderately heated, though still friendly, exchange. Eventually, as matters escalated, I asserted that the word "transportation" was superfluous to the English language and would not be found in any proper dictionary, and a small wager was made. The Oxford English Dictionary provided me with a loss. Oh, I think I could have argued my way out of the fact that it includes the word as "Means of transport or conveyance. U.S."
After all, the venerable dictionary clearly identifies the syllabically augmented form as a purely U.S. phenomenon. Sadly for me, however, I had forgotten a number of other correct uses, including the "removal or banishment criminal to a penal settlement." Traveling on the MBTA's Green Line can be a punishing experience, so that, perhaps is where they got the idea.

As you travel farther west in the U.S., the First Law is less honored. Consider the windy city's "Chicago Transit Authority." Admirable and appropriate brevity!

So, via O'Hare International Airport, on to San Francisco and the MRS Spring Meeting. Here is the home of the contracted phrase and the excised syllable. The First Law is at best ignored and at worst inverted out here. The attendees of the Spring Meeting, heavily influenced by the pace and pressure of Silicon Valley, have no time for extra words or syllables, even when they add clarity. How many of us were confused when we first heard the word "polysilicon?" No, it is not some new polymerized form of an element so close to carbon in the periodic table that we wondered if it could be done. Proper chemical nomenclature notwithstanding, "polysilicon" is just short for "polycrystalline silicon." Out here, the laws of thermodynamics also appear to be suspended, so evidently only one element bonds with oxygen, making it unnecessary to specify what kind of "oxide" is being discussed, although it is occasionally appropriate to indicate where it is, as in the ubiquitous (and increasingly troublesome) "gate oxide." Self-aligned silicide, whether it be of titanium, cobalt, nickel, or palladium, is known as "salicide" in one of the most efficient contractions created to date.

Well, here is a chance to heighten your linguistic awareness, and maybe gain a little fame at the same time: Send us your favorite phrase of either the augmentation (pro First Law) or diminution (inverse First Law) type to Bulletin@mrs.org. We will define the "efficiency" of the phrase, on the basis of the percentage increase or decrease in the number of letters and/or syllables relative to the simplest clear expression of the same idea, and publish the most outrageous submissions in this column. Have fun (or maximize your enjoyment) with this.

Alex KING 